\title{
Review on the Impact of Invasive Alien Weed Tree Distributed in Afar Regional State and Some Parts of Oromia Region, Ethiopia
}

\author{
Megersa Daba Regessa* \\ Ethiopian Institute of Agricultural Research, Werer agricultural Research Center
}

\begin{abstract}
Prosopis juliflora belongs to fabaceae family, growing to height of 12 meters and 1.2 meter trunk diameter. It is native to Caribbean, South and Central America. Currently, distributed to Africa, where it invades over four million hectares, threatening crops and range land production, desiccating water resources and displacing native flora and fauna. In Ethiopia, it is one of the most invasive alien species causing economic and environmental harm. Specifically, it invaded Afar, Somali and Oromia regions more to the east and southeast direction of the country. Regardless of its negative effects, the tree has potential uses as fuel, charcoal, fodder, gum, food, ethanol source, biochar, biocontrol, windbreaks, shade, soil stabilization, construction and furniture materials. Therefore, this paper reviewed the impacts, merits, demerits and management aspects of prosopis. Thus, many scholars reported that there are high impacts of prosopis on agricultural production and productivity, biodiversity especially on local flora and fauna, livestock's healths and the livelihoods of pastorals. Alarmingly increment of prosopis invasion covers 3, 60500 (3.8\%) in Afar region and 12,000 hectares in Dire Dawa administration. Due to its fast growing habit, rapid multiplicative and vigorous coppicing ability, it is extremely invading arid and semiarid area of the country. Eventhough, weak awareness of pastorals and agropastorals, manually controlling practices, cost-benefit they gain were reported to discouraging them from controlling. If not strategic controlling managements is taken $50 \%$ land of Ethiopia was reported to be suitable for prosopis infestation. Thus, participation of government and/or non-government in community mobilization, technology transfer, private sector, and supply of resources are critical to manage. Finally, there should be an urgent need to develop management strategies that are environmentally friend and economically viable.
\end{abstract}

Keywords: alien, crop, Dire Dawa, fabaceae, pastorals, prosopis

DOI: $10.7176 / \mathrm{JNSR} / 10-8-01$

Publication date: April $30^{\text {th }} 2020$

\section{Introduction}

Prosopis juliflora belongs to family fabaceae (leguminosae), sub-family mimosoideae and genus prosopis (Pasiecznik et al., 2001). Prosopis juliflora here after prosopis is an evergreen growing to a height of 12 meters and with a trunk diameter of 1.2 meters. It is an invasive plant native to South America, the Caribbean, and Central America (Obonyo et al., 2017). Currently, it is distributed to Africa, where it invaded over 4 million hectares, threatening crop and rangeland production, desiccating water resources, and displacing native flora and fauna (Witt, 2010; Zimmerman et al., 2006) cited in Wakie et al. (2012).

Prosopis was introduced in Ethiopian lowland in $1970^{\text {th }}$ to solve deforestation, desertification and land degradation (Wakie et al., 2012; Rettberg, 2014). Now, it is one of the most invasive alien species causing economic and environmental harm in Dire Dawa areas of Oromia, Afar and Somali regions in the east and southeast of the country (Abdulahi et al., 2017). It is an alien tree species in Ethiopia, has invaded more than 12,000 hectares in Dire Dawa administration (BoARD, 2009) cited in Haji and Mohammed (2013) and over 360,500 ha of land in the Afar region of the country (Tilahun et al., 2016). Its rapid spreading in the Allideghi wildlife reserves and Awash National Parks biodiversity, rangelands, croplands and forests threatening pastorals and agro-pastorals livelihoods (Tessema, 2012). Prosopis has the capacity to decrease the composition and diversity of plant species and adverse effects on crop yield, animals and human health. Its ability to adapt a wide range of climatic condition, effective dispersal mechanism, its allelopathic effect, prolific seeds nature, having a large seed bank in the soil environment, fast growing and vigorous coppicing ability are factors favoring its rapid distribution among the principal factors (Obonyo et al., 2017). When the economic benefit of the tree considered, the tree has potential uses as fuel, charcoal, fodder, food, biochar, bio-control,soil stabilization, windbreaks, shade, construction and furniture materials. It can be also be used against different disease and ameliorated environmental conditions through carbon sequestration (Tessema, 2012; Abdulahi et al., 2017). Silva et al. (2011) reported that prosopis pods are an interesting substrate for ethanol production using submerged fermentation. Nowadays, the imbalance between its utilization and crisis in invasions of the alien tree made debates to efficient use and/or complete eradication to reverse its adverse effects on the agro-pastoral households. Therefore, the objective of this paper is to review the impacts, merits and demerits of invasive alien prosopis distributed in Afar regional state and some parts of Oromia region. 


\section{Impacts of Prosopis juliflora in Afar Regional State and Some Parts of Oromia Region 2.1. Impacts on irrigated land and crop production}

Invasion into crop fields reduces crop productivity apart from invading the land available for crop production and disturbing the irrigation canals which implies extra costs for clearing McConnachie et al. (2012) cited in Tilahun et al. (2016). It was reported by Admasu (2008) invasion of prosopis in Afar region of Ethiopia, revealing the serious potential impacts of invasive plant species on people's food security and livelihoods. Haji and Mohammed (2013) reported that in Dire Dawa areas an average annual income of agro-pastoral households from crop sale increased by 839.31 Birr $(25.85 \%)$; though it was non-significant from livestock and their products sales which were significantly decreased by 780.74 Birr $(28.82 \%)$. The increments from crop sale as prosopis and its contribution to soil and water conservation while decrement of livestock's was as result of reduced grazing land and loss of palatable grass species due to prosopis.

\section{2..2. Impacts on Animal production}

The leaves of prosopis contain various chemicals including tannins, flavonoids, steroids, hydrocarbons, waxes and alkaloids (Pasiecznik et al., 2001). These are known to affect palatability to livestock. Prosopis poisoning animals, causing chronic diseases and to present signs of poisoning such as twisting of necks and drooling of saliva, dropped jaw, tongue protrusion and loss of food from the mouth (Koyira, 2015; Almeida et al., 2017). Some of the symptoms discussed above were observed on sheep ingested a diet containing at least $80 \%$ of prosopis pods for 21 months. The hard seeds of prosopis lodge between gums and teeth, leading to inflammation and livestock jaws are eventually disfigured as fig $1 \mathrm{C}$ below. It was also reported that in Afar region of Ethiopia, some cattle died due to injury from prosopis thorns. Once they wounded on their skins and hooves they are not able to travel and feed themselves thus, they lose their condition and finally die (Admasu, 2008).
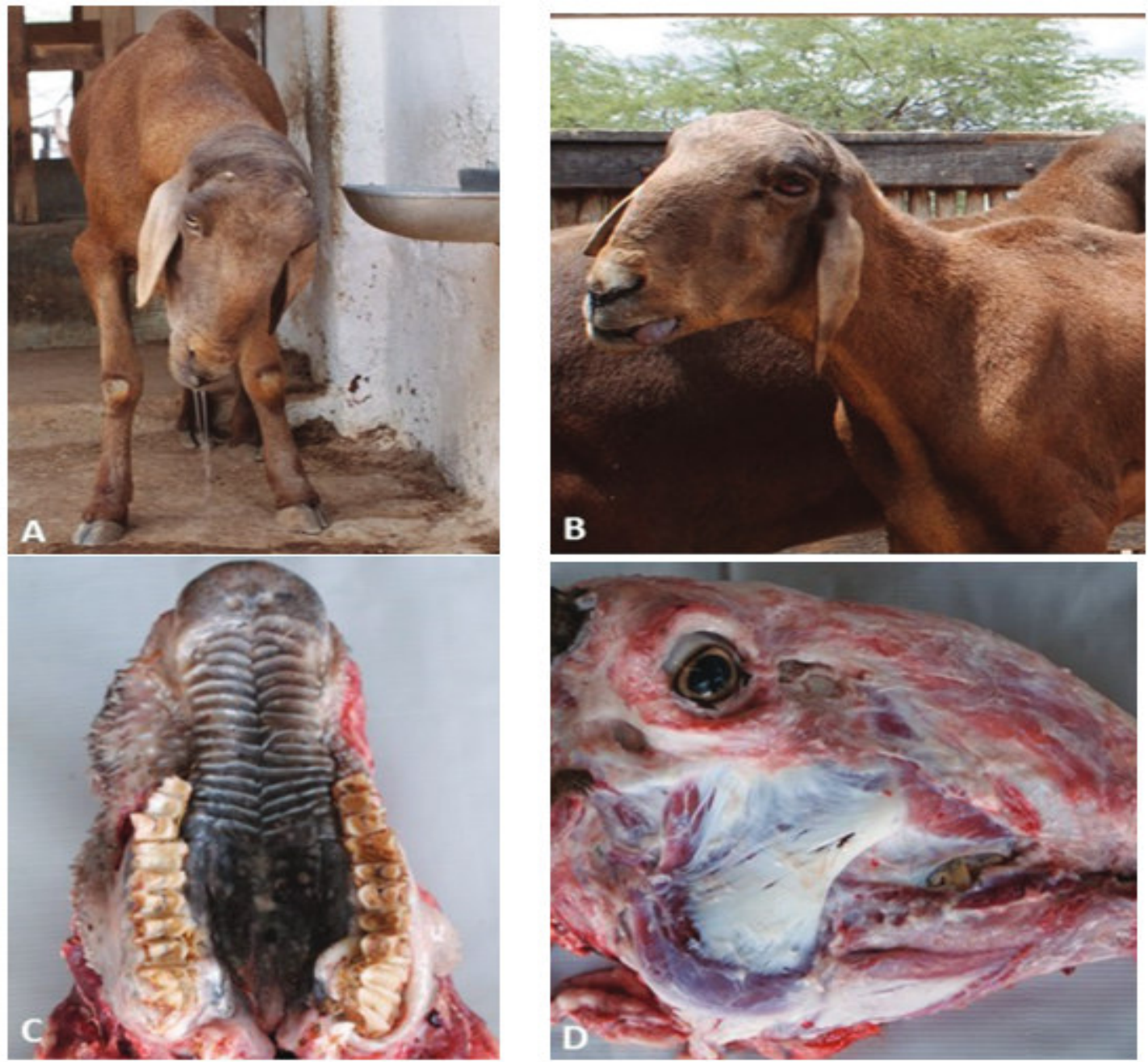

Figure 1: Spontaneous poisoning by Prosopis juliflora. A. Sheep with depression, drooling, head tilt. B. tongue protrusion. C. Molars exceeding the plane of occlusion ruined and tilted to the palatine plane. D. Slight depression of the masseter muscle, suggesting atrophy

Source: Almeida et al. (2017) 


\subsection{Impacts on Biodiversity}

Prosopis juliflora has negative impacts on local farmlands and pasture lands. It creates a physical barrier against seedlings of other plant species and makes establishment very difficult. Since its branches are much, dense, and have evergreen leaves, sunlight will not reach the ground and plants under the canopy of the prosopis will not have enough sunlight that is very crucial for photosynthesis. This may result in the death of plants under the canopy of the prosopis (Pasiecznik et al., 2001). It was reported by Koyira (2015), prosopis affects density, richness, diversity and evenness of other species. Most of the interviewed respondents live around the reserve responded that $66.25 \%$ of Alledeghi reserve severely affected by prosopis encroachment as figure 2 below.

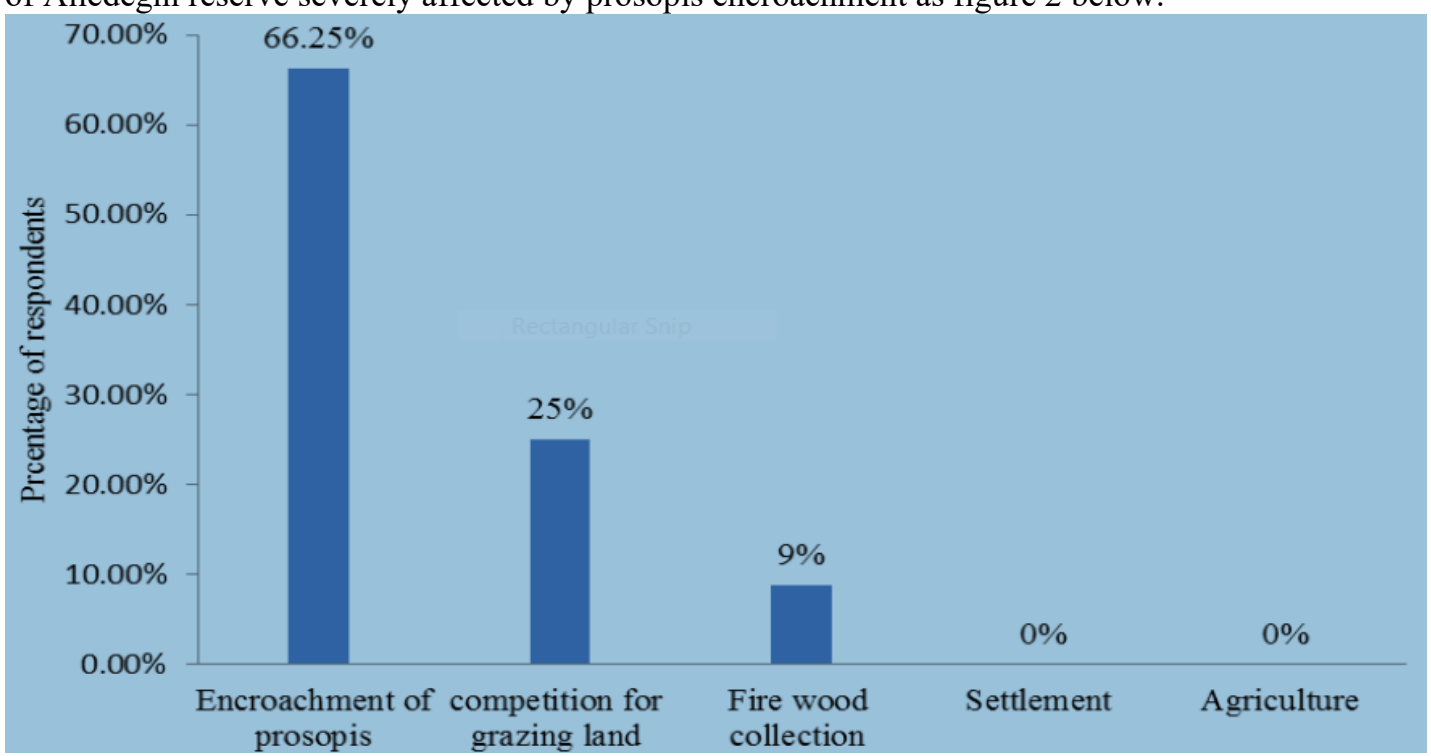

Figure 2: Respondents' response to factors severely affecting Alledeghi Reserve Source: Koyira (2015)

\subsection{Other negative impacts of prosopis}

The thorn of prosopis causes inflammation when injuries occur. The injury does not heal easily despite intensive medical treatment (Birhanu and Tesfaye, 2006). According to Duck (1983), the wood is also known to cause dermatitis when it burns. The thick prosopis thickets have also constrained the mobility of people and blocked access to land, roads and watering points (Birhanu and Tesfaye, 2006). The recent study by Muller et al. (2017) in Mali revealed that prosopis encourages malaria parasite transmission capacity of African malaria vector mosquitoes. This is due to a rich sugar source like prosopis had a significant effect on mosquito populations with four to six times more females, and up to eight times more males, than in villages without this invasive shrub.

\subsection{Positive impacts on climate change}

Prosopis positively contribute to change the degraded land of arid and semi-arid regions. It formed a mono-specific prosopis thicket in which the scenery and microclimate of the area can be changed as figure $3 \mathrm{~A}$ below. It was reported by Treydte and Birhane (2014) prosopis enhanced biomass and Carbon stocks can be positive in terms of climate change mitigation (micro-climate, soil moisture content, organic matter, $\mathrm{C}$-trade may be alternative income generation).

\section{A}

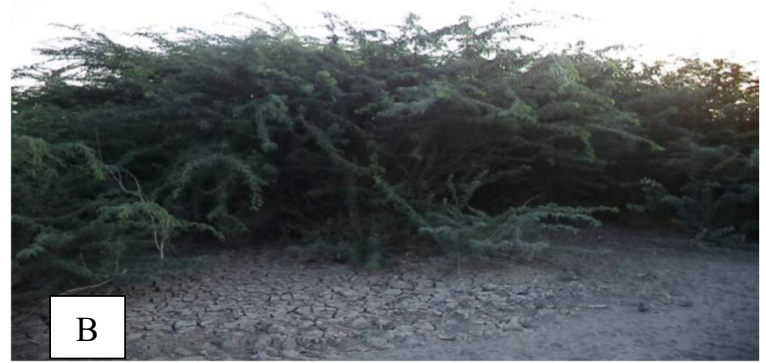

Figure 3: Prosopis change areas in Afar region A. Monospecific thicket of Prosopis B. Grow in extreme adverse condition

Source: (Mehari, 2015; Koyira, 2015) 
Prosopis is known to be drought and salt tolerant and invaded several degraded and bare sandy soils (Birhanu and Tesfaye, 2006). In the middle Awash reports have shown that during the 2003 cropping season only about 500 hectares of previously abandoned cotton farm field due to the soil salinity problem was reclaimed after being colonized by prosopis. Similarly, nearly 300 hectares of abandoned farmlands were also reclaimed at lower Awash (Birhanu and Tesfaye, 2004). Prosopis have positive effects on the soil layer (Birhanu and Tesfaye, 2006; Ilukor et al., 2014). Thus, it is an important species for improvement of soil fertility as well as mitigation of desertification, which is a major problem of irrigated agriculture in arid and semiarid regions in Ethiopia. These positive soil characteristics can be used for consecutive planting of native species on cropping fields. In some studies, the physicochemical property of soil under prosopis canopy was found to be better than the adjacent open field (e.g. El Fadl, 1997, cited in Mwangi and Swallow, 2005.) which may be due to nitrogen fixation, leaf litter addition and change in soil structure due to deep tap root system (Pasiecznik et al., 2001). The tree can be used as fuel, charcoal, fodder, food, biochar, biocontrol, windbreaks and shade, construction and furniture materials in addition to soil physicochemical and environment modification (Abdulahi et al., 2017).

\subsection{Suitability, current distribution and future invasion of prosopis}

According to Wakie et al. (2012), the study results based on the environmental envelope model indicated half land of Ethiopia may be at risk of prosopis invasion. Regions that have the highest risk of invasion include Afar, Somali and Dire Dawa. Suitable habitats are also present in Tigray, Oromia, Amhara, Southern Nations and Gambella regions (Wakie et al., 2012). Variables like distance to water, distance to road, soil types, slopes, aspects and elevation were used to predict potential distribution, where the distance to water, distance to road, soil types, and slope found to have the greatest predictive contributions. Accordingly, it was categorized as suitable and nonsuitable habitats as the following figure 4 map.

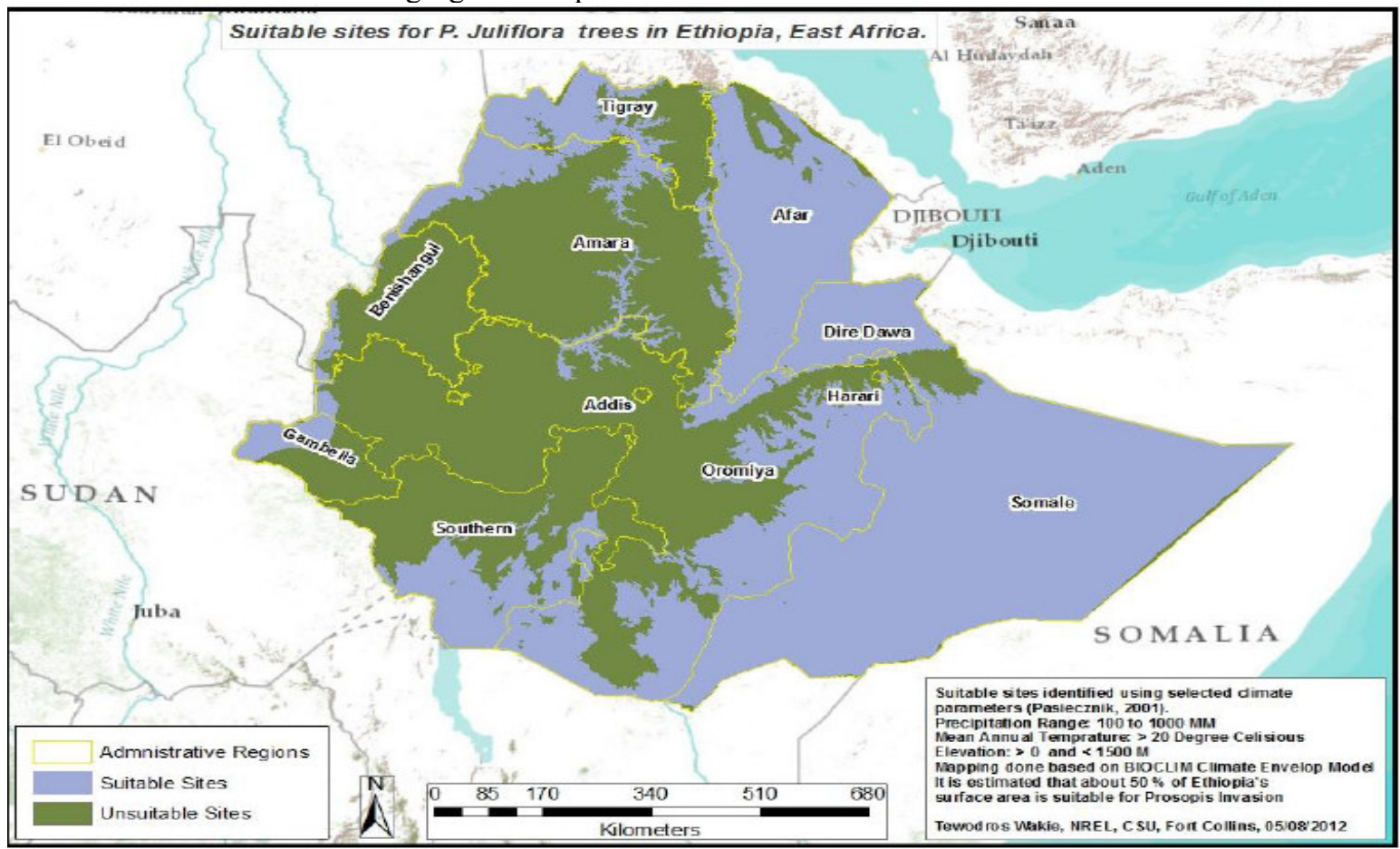

Figure 4: Suitable habitat (blue) and potential distribution map for prosopis tree in Ethiopia Source: Wakie et al. (2012)

In Afar region, visual inspection of the recent prosopis distribution map shows that infestation is dominant in the Gabi, Awsi, and Hari administrative zones (Wakie et al., 2014). The authors used time-series of MODIS Enhanced Vegetation Indices (EVI) and Normalized Difference Vegetation Indices (NDVI) with $250 \mathrm{~m}^{2}$ spatial resolution as remote sensing predictors for mapping distributions, while World Clim bioclimatic products and generated topographic variables from the Shuttle Radar Topography Mission product (SRTM) were used to predict potential infestations. According to the model, the northern most administrative area, Kilbert, is the least invaded. The banks of Awash River are heavily invaded by prosopis. Area calculations of model results showed that the current predicted distribution and potential extent of distribution of prosopis invasion cover 3,605 $(3.8 \%)$ and $5,024(5.3 \%) \mathrm{km}^{2}$ of the Afar region respectively. 


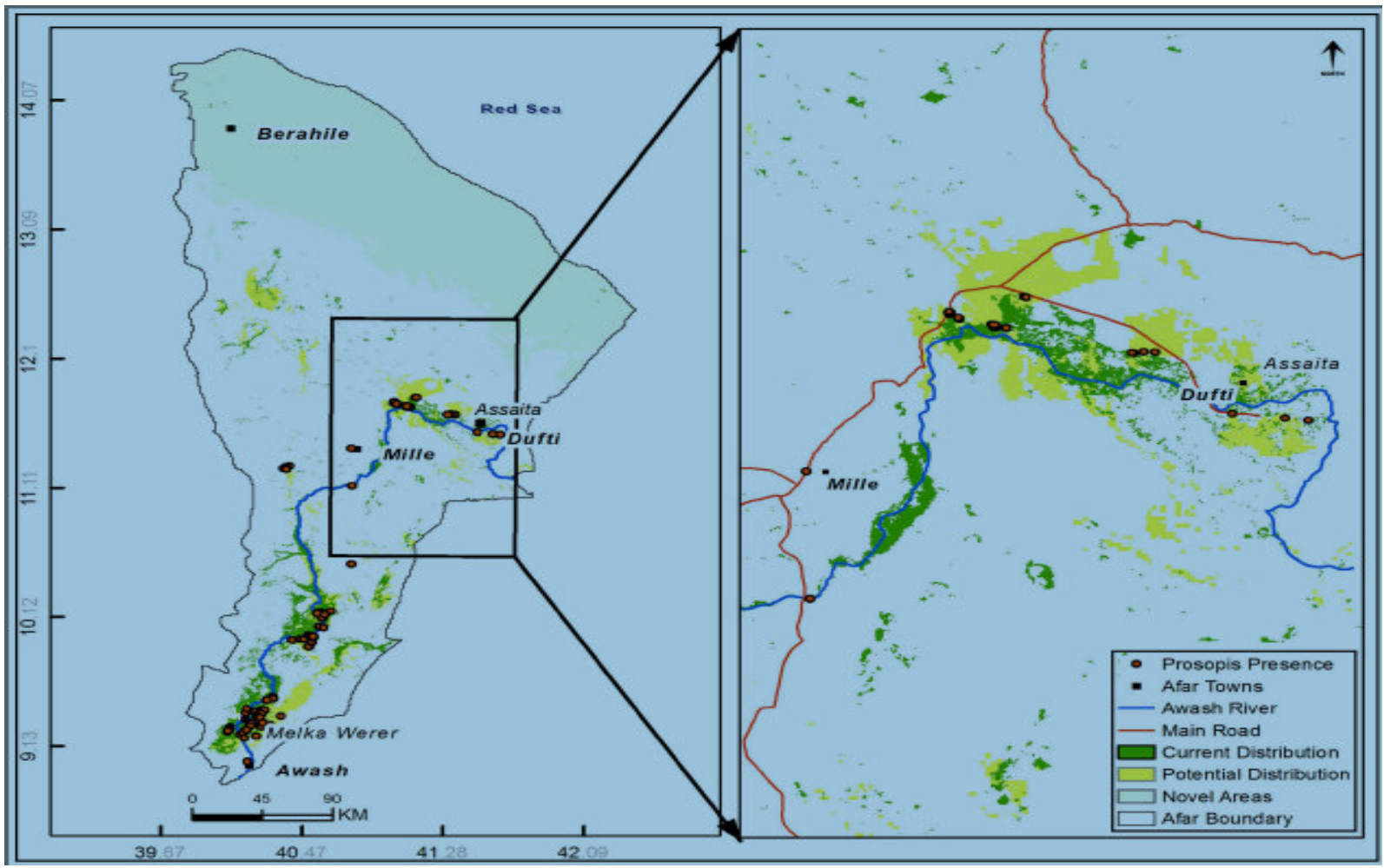

Figure 5: Distribution map of Prosopis in Afar region

Source: Wakie et al. (2014)

\subsection{Management practices of prosopis invasion}

Afar pastorals practicing to control prosopis invasion by cutting, hand pulling and both cutting and burning, while $37.5 \%$ of the respondents were practicing only cutting Table 1 . However due to its fast growing habit unless external supports like community mobilization, technology transfer, private sector participation and supply of resources were not taking part it is difficult to eradicate by such attempts only. In another way it was reported that $84 \%$ of the respondents prefer an intervention involving complete eradication, but eradication of prosopis infested lands were costly which is in average $11.70 \mathrm{USD} /$ household/year in cash and tedious which takes 37 days/household/year in labor to manage (Tilahun et al., 2016). According to Abdulahi et al. (2017) controlling methods like the hand, manual, mechanical, chemical, and biological were effective. It was reported that two times applications of systemic translocated herbicides such as Mera-71 (Glyphosate) and 2.4- found better to control regrowth of prosopis (Shanwad et al., 2015). Though, there should be strong integrative management strategies that are environmentally friend and economically viable. Hence, control by utilization has been pointed as effective management of this tree weed species. Whereas, practices in pastorals of Afar households to control the invasion of prosopis stated as below (Table 1).

Table 1. Practices in pastorals of Afar households to control the invasion of prosopis

\begin{tabular}{lcc}
\hline Methods used to control & Respondents practiced control measures & Respondents in \% \\
\hline Cutting & 30 & 37.50 \\
Both cutting and burning & 23 & 28.75 \\
Burning & 14 & 17.50 \\
Hand pulling & 13 & 16.25 \\
\hline
\end{tabular}

Source: Koyira (2015)

Currently, pastorals in Afar inhabitants are using prosopis for different purposes such as fuel wood, fencing, house construction, charcoal making, and pods for livestock feed (Admasu, 2008). According to Obonyo et al. (2017), in the East African communities (e.g. Sudan and Kenya) technologically advanced, tree's seed used as raw materials for animal feed and human food production, sensitization of the communities on the medicinal use of the plant. A study reported by Silva et al. (2011), revealed that prosopis pods as an interesting substrate for ethanol production using submerged fermentation and Yemata (2014) reported the wood itself served as an ethanol feedstock. In this regard in our country, urgent action should be made in order to utilize as raw materials for ethanol gas production and control the invasiveness of this alien weed tree in a sustainable way. It was also reported that it provides other economic benefits including through production of gum and as honeybee fodder combined with some medicinal values and as an anti-fungal agent (Etana, 2013). Generally, in the future such a like utilization 
needs studies and professionals in order to contribute their roles in considering the usage of prosopis as raw materials as well avoiding invasion without use and purpose.

\section{Summary and conclusions}

Generally, scholars reported that there are enormous impacts of Prosopis juliflora on the environment and local community either positively or negatively. In Afar region and some parts of Dire Dawa areas, impacts of prosopis on agricultural land production and productivity, biodiversity especially local flora and fauna, livestock's healths and the livelihoods of pastorals are on alarming rate. A recently report from Mali also stated that, prosopis encourages malaria parasite transmission capacity of African malaria vector mosquitoes. However, the tree has potential uses as fuel, charcoal, fodder, gum, food, ethanol source, biochar, biocontrol, windbreaks, soil stabilization, shade, construction and furniture materials. It serves against different diseases, medicinal values as antifungal agent and ameliorated environmental conditions through carbon sequestration. Currently the balances were missed and negative effects weigh more. Even though pastorals are willing to control the invasion manually, due to fast growing, rapid multiplicative nature and vigorous coppicing ability they were discouraged. As result, currently predicted invasion covers 360500 (3.8\%) in Afar region and 12,000 hectares in Dire Dawa administration. If not strategic controlling managements is taken 50\% land of Ethiopia is reported to be suitable for prosopis infestation. Thus, participation of government and/or non-government in community mobilization, technology transfer, private sector, and supply of resources are a key to manage. Thus, developing management strategies with the local pastorals, agro pastorals and experts are mandotory to use wisely. It is a good source of ethanol gas; hence, developing a protocol and making industrial based controlling. Grouping peoples, providing incentives and training with technology and skills are the options to control the invasion through utilization. Finally, there should be an urgent need to develop management strategies that are environmentally friend and economically viable.

\section{References}

Abdulahi, M.M., Ute, J.A. and Regasa, T. (2017). Prosopis juliflora L: Distribution, Impacts, and Available Control Methods in Ethiopia. Tropical and Subtropical Agro ecosystems, 20(1): 75-89.

Admasu, D. (2008). Invasive Plants and Food Security: the case of Prosopis juliflora in the Afar region of Ethiopia. ARM-Africa for IUCN Bangor: University of Wales.

Almeida, V.M., Rocha, B.P., Pfister, J.A., Medeiros, R.M., Riet-Correa, F., Chaves, H.A., Silva Filho, G.B. and Mendonça, F.S. (2017). Spontaneous poisoning by Prosopis juliflora (Leguminosae) in sheep. Pesquisa Veterinária Brasileira, 37(2): 110-114.

Berhanu, A. and Tesfaye, G. (2006). The Prosopis dilemma, Impacts on dry land biodiversity and some controlling methods. $J$. of the Drylands 2: 158-164.

Bureau of Agriculture and Rural Development (BoARD) (2009). Annual report. Dire Dawa.

Duke J.A. (1983). Prosopis DC. Handbook of energy crops, Unpublished.

El-Fadl, M.A. (1997). Management of Prosopis juliflora for use in agroforestry systems in the Sudan (No. 16). Department of Forest Ecology, University of Helsinki.

Etana, B., 2013. Opportunities and Management Options of an Invasive Exotic Species, Prosopis Juliflora (Sw.) Dc. (Fabaceae) In Ethiopia: Int. J. Int sci. Inn. Tech. Sec. A, 2(1): 59-65.

Haji, J. and Mohammed, A. (2013). The Economic impact of Prosopis juliflora on agro-pastoral households of Dire Dawa Administration, Ethiopia. African Journal of Agricultural Research, 8(9): 768-779.

Ilukor, J., Birner, R., Tilahun, M. and Getu, S. (2014). A social-economic assessment of the impact of Prosopis juliflora invasion and participative management approaches in the Afar Region, Ethiopia. Managing Prosopis Juliflora for better (agro-) pastoral Livelihoods in the Horn of Africa, p.30.

Koyira, S.T. (2015). Impact of Prosopis juliflora L. (Fabaceae) on Plant Biodiversity at Alledeghi Wildlife Reserve and Surrounding Local Community, Ethiopia.

McConnachie, M., Cowling, R., vanWilgen, B., McConnachie, D. (2012). Evaluating the cost-effectiveness of invasive alien plant clearing: a case study from South Africa. Biol. Conserv. 155: 128-135.

Muller, G.C., Junnila, A., Traore, M.M., Traore, S.F., Doumbia, S., Sissoko, F., Dembele, S.M., Schlein, Y., Arheart, K.L., Revay, E.E. and Kravchenko, V.D. (2017). The invasive shrub Prosopis juliflora enhances the malaria parasite transmission capacity of Anopheles mosquitoes: a habitat manipulation experiment. Malaria journal, 16(1), p.237.

Mwangi, E. and Swallow, B. (2005). Invasion of Prosopis juliflora and local livelihoods: a Case study from the Lake Baringo area of Kenya. Nairobi, Kenya: World Agroforestry Centre.

Obonyo,C.O., Zhua H., Hea W., Chinopfukutwa G. L. (2017). How do East African Communities Cope with the Impacts of Prosopis juliflora (Mesquite) Invasion? A Review

Pasiecznik, N. M., Felker, P., Harris, P. J. C., Harsh, L. N., Cruz, G., Tewari, J. C. (2001). The Prosopis juliflora - Prosopis pallida Complex: A Monograph. Coventry, UK: HDRA

Rettberg, S. (2014). The spread of Prosopis juliflora in the wetlands of the Middle Awash Basin. In: Managing 
Prosopis juliflora for better (agro-) pastoral Livelihoods in the Horn of Africa. Proceedings of the Regional Conference, Addis Ababa, 2014.

Shanwad, U.K., Chittapur, B.M., Honnalli, S.N., Shankergoud, I. and Gebremedhin, T. (2015). Management of Prosopis juliflora through Chemicals: A Case Study in India. Management, 5(23).

Silva, C.G.M.D., Andrade, S.A.C., Schuler, A.R.P., Souza, E.L.D. and Stamford, T.L.M. (2011). Production of ethanol from mesquite [Prosopis juliflora (SW) DC] pods mash by Zymomonas mobilis in submerged fermentation. Scientia Agricola, 68(1): 124-127.

Tesfaye, G. and Birhanu, A. (2004). Working manual for Ecological impacts assessment and management of Prosopis juliflora (Sw.) DC. In Eastern Ethiopia.

Tessema, Y.A. (2012). Ecological and economic dimensions of the paradoxical invasive species-Prosopis juliflora and policy challenges in Ethiopia. Journal of Economics and Sustainable Development (www. iiste. org), 3(8): 62-70.

Tilahun, M., Birner, R. and Ilukor, J. (2016). Household-level preferences for mitigation of Prosopis juliflora invasion in the Afar region of Ethiopia: a contingent valuation. Journal of Environmental Planning and Management, 60(2): .282-308.

Treydte, A.C. and Birhane, E. (2014). Ecological challenges and potential carbon storage benefits of Prosopis juliflora in Afar. Managing Prosopis Juliflora for better (agro-) pastoral Livelihoods in the Horn of Africa, p.20.

Wakie, T. T, Evangelista, P. H, Jarnevich, C.S., Laituri, M. (2014). Mapping Current and Potential Distribution of Non-Native Prosopis juliflora in the Afar Region of Ethiopia. PLoS ONE 9(11)

Wakie, T., Evangelista, P. and Laituri, M. (2012). Utilization assessment of Prosopis juliflora in Afar region, Ethiopia. US Forest Service, USDA Office of International Programs, USAID Pastoral Livelihoods Initiative II Project (PLI II).

Witt, A.B. (2010). Biofuels and invasive species from an African perspective-a review. Gcb Bioenergy, 2(6): 321329.

Yemata, T. A. (2014). Optimization of Acid Hydrolysis in Ethanol Production from Prosopis Juliflora. American Journal of Energy Engineering, 2(6): 127-132.

Zimmermann, H.G., Hoffmann, J.H. and Witt, A.B.R.. (2006). A South African perspective on Prosopis. Biocontrol News and Information, 27: 6-9. 